\title{
THE EFFECT OF HUMIC ACIDS ON THE REMOVAL OF ATRAZINE FROM WATER IN A CONTINUOUS PHOTOCATALYTIC MEMBRANE REACTOR
}

\author{
KARABELAS A.J.* \\ PLAKAS K.V. \\ SARASIDIS V.C. \\ PATSIOS S.I.
}

\author{
Natural Resources and Renewable Energies Laboratory \\ Chemical Process and Energy Resources Institute \\ Centre for Research and Technology - Hellas \\ P.O. Box $60361,6^{\text {th }} \mathrm{km}$ Charilaou-Thermi Road, Thermi \\ Thessaloniki, GR 57001, Greece
}

Received: $16 / 04 / 2012$

Accepted: 24/05/2014

*to whom all correspondence should be addressed:

Available online: 26/05/2014

e-mail:karabaj@cperi.certh.gr

\begin{abstract}
This paper examines the effect of humic acids $(\mathrm{HA})$ and other solution constituents $\left(\mathrm{Ca}^{2+}, \mathrm{Mg}^{2+}, \mathrm{Na}^{+}\right)$, frequently encountered in potable water sources, on the removal of a well-known herbicide, atrazine (ATR), by a laboratory-scale pilot Photocatalytic Membrane Reactor (PMR) system. Experimental results with different HA concentrations, in the presence (or not) of background cations, demonstrate the attainment of steady-state operation with constant degradation efficiencies and controlled membrane fouling phenomena. The excellent performance of the system is attributed to the efficient photocatalytic degradation of the dissolved organics, which is enhanced by steric interactions between the HA-ATR pseudo-complexes and the membrane. The successful laboratory tests hold promise for practical water treatment applications of the proposed PMR system.
\end{abstract}

Keywords: AOPs, atrazine, humic acids, hybrid ultrafiltration-photocatalysis, mineralization

\section{Introduction}

Advanced oxidation processes (AOPs) have emerged as an important class of technologies for accelerating the oxidation (and hence contaminant removal) of a wide range of organic contaminants in polluted water and wastewater (Esplugas et al., 2007; Matilainen and Sillanpää, 2010). Among the different AOPs, heterogeneous photocatalysis using semiconductor catalysts (e.g. UV/ $/ \mathrm{TiO}_{2}$ ) has been demonstrated to be very effective against a number of refractory organic pollutants of natural (e.g. humic substances, polysaccharides) or anthropogenic origin (e.g. pesticides, pharmaceutically active compounds, industrial chemicals, etc) frequently encountered in drinking water sources (Ahmed et al., 2011; Augugliaro et al., 2012). However, the application of this process at large scale is constrained by the inconvenience of catalyst particle separation from the treated water at the end of operation. In this direction, hybrid processes coupling heterogeneous photocatalysis and membrane separation present significant potential for water treatment applications. The so-called Photocatalytic Membrane Reactors (PMR) exhibit important advantages which include the catalyst confinement in the reaction environment and its use over a long period of time, the control of the residence time of pollutants in the photocatalytic reactor, and the possibility of operating in continuous mode, simultaneously separating catalyst particles and treated effluent (Mozia, 2010).

The efficiency of PMR process, for degrading a rather broad range of organic contaminants of natural (e.g. alginates, humic acids) and anthropogenic (e.g. diclofenac) origin, has already been proven in this laboratory (Sarasidis et al., 2014; Patsios et al., 2013; Sarasidis et al., 2011). The encouraging results so 
far have been obtained by treating separately single-solute aqueous solutions. However, the removal efficiency against the organic micropollutants can be altered in the presence of natural organic matter and/or other inorganic constituents frequently encountered in source waters (e.g. $\mathrm{Ca}^{2+}, \mathrm{Mg}^{2+}, \mathrm{HCO}_{3}{ }^{-}$) as a result of the antagonistic uptake of the highly reactive hydroxyl radicals $\mathrm{HO}^{\circ}$ that are produced during catalyst activation by UV irradiation within the photocatalytic reactor. The effect of the ionic strength, of the natural organic matter (NOM) and of other environmental parameters, such as $\mathrm{pH}$ and alkalinity, on organic micropollutant photocatalytic degradation has been addressed in several studies. For instance, Autin et al. (2013) observed a reduction in the photocatalytic degradation rate of the pesticide metaldehyde by an average value of $13 \%$ and $38 \%$ for mole ratios of metaldehyde/background-NOM $1: 10$ and 1:100, respectively. A further increase of the ratio in favour of NOM led to greater inhibition of the pesticide degradation as a result of the reduced proximity of the pollutant to the surface of the catalyst $\left(\mathrm{TiO}_{2}\right)$. In the same work, the increase of alkalinity had a detrimental effect on metaldehyde degradation, which was reduced to $45 \%$ compared to the system without alkalinity, where $93 \%$ of the pesticide was degraded (Autin et al., 2013). Doll and Frimmel (2005a) reported that the presence of NOM promoted the solar UV-light photodegradation of the drugs carbamazepine, clofibric acid and iomeprol but inhibited the photocatalytic degradation in the presence of $\mathrm{TiO}_{2}$ (Doll and Frimmel, 2005b). Another paper by Andreozzi et al., (2002) reported the inhibition of the photodegradation of carbamazepine in the presence of HA. Such inhibition was not observed by Haroune et al., (2014) when $\mathrm{TiO}_{2}$ was used as catalyst; however these authors observed an inhibition by humic acids and tannic acids in the presence of $\mathrm{ZnO}$. These contradictory results are probably linked to the different type of NOM and experimental conditions used in each work.

While researchers have investigated the efficiency of photocatalysis on the degradation of organic micropollutants in the presence of NOM, similar studies with membrane photoreactors are rather scarce. The majority of the relevant publications refer to PMR studies with pure aquatic solutions of the target micropollutants (Doll and Frimmel, 2005c; Molinari et al., 2008). However, the overall efficiency of a PMR system can vary significantly when treating real source waters (Benotti et al., 2009). The presence of NOM and of other constituents can alter not only the photocatalytic efficiency of the system but also the rejection of the organic micropollutants during the membrane filtration. Previous studies in this laboratory showed that naturally occurring organic compounds tend to form complexes with divalent cations and pesticides, and to foul membrane surfaces with both phenomena having a significant effect on pollutant rejection (Plakas and Karabelas, 2009; 2011). Taking into account these observations, it is of great practical interest to assess the photocatalytic degradation and removal efficiency of a continuous PMR system treating toxic organic micropollutants together with background organic materials at mass ratios similar to those measured in typical freshwater sources. The current work investigates the degradation of a typical herbicide (atrazine) in the presence of dissolved humic acids (HA) at a mass ratio $20 \mu \mathrm{g}_{\text {atrazine }} / \mathrm{mg}_{\mathrm{HA}}$. Atrazine (1-chloro-3-ethylamino-5-isopropylamino-2,4,6triazine) was selected based on the knowledge gained in this laboratory from previous NOM-herbicides filtration studies (Plakas and Karabelas, 2009; 2011). Although banned in EU since 2004 due to its endocrine disrupting effect and its persistence in groundwater and surface water sources (Ackerman, 2007), this compound is still used in more than 60 countries around the world - in Africa, North and South America, Australia, Asia and the Middle East, where traces of atrazine and its metabolites are frequently detected in potable water sources (USEPA, 2014; APVMA, 2014).

\section{Experimental work}

\subsection{Photocatalytic membrane reactor (PMR)}

The PMR system designed and constructed in this laboratory is comprised of two main parts, i.e. a jacketed cylindrical vessel with an effective volume of $2.3 \mathrm{I}$ (photocatalytic reactor) and a rectangular Plexiglas vessel with an effective volume of 0.7 I where a UF membrane module (of total surface area $0.097 \mathrm{~m}^{2}$ ) is submerged (Fig. 1). Four 24W black light lamps (Actinic BL PL-L 24W/10/4P Philips) emitting at $365 \mathrm{~nm}$ are employed as UV-A light source of the system. Both the operating permeate flux and the 
UV-A radiant power per unit volume are kept constant at approx. $15 \mathrm{I} \mathrm{m}^{-2} \mathrm{~h}^{-1}$ and $6.57 \mathrm{~W} \mathrm{I}^{-1}$, respectively. Air is supplied in the photoreactor at a rate of $0.0012 \mathrm{Nm}^{3} \mathrm{~min}^{-1}$. An automated periodic backwashing operation is implemented to mitigate membrane fouling. A centrifugal pump is used to recirculate the catalyst suspension through the photoreactor and the membrane vessel at a volumetric rate of approx. $81 \mathrm{~min}^{-1}$. Details on the construction of the photoreactor and the experimental system used in this study, which can run unattended for long time periods, can be found elsewhere (Karabelas et al., 2013; Sarasidis et al., 2014).

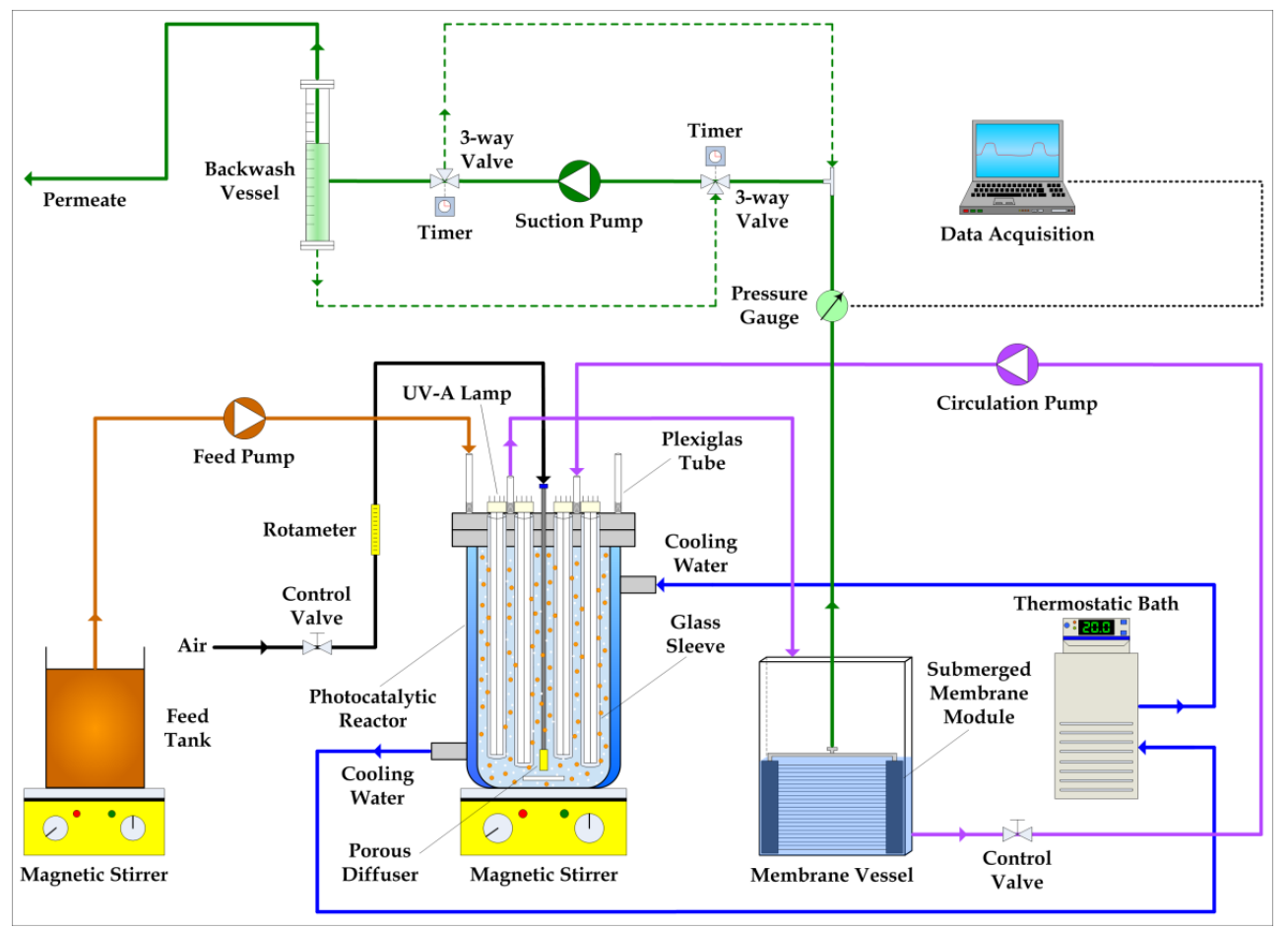

Figure 1. Schematic diagram of the laboratory PMR system

\subsection{Materials and methods}

The photocatalyst was titanium dioxide (Aeroxide P25, Degussa-Evonik, Germany) at concentration $0.50 \mathrm{~g} \mathrm{l}^{-1}$ which was found to be near optimum for diclofenac degradation (Sarasidis et al., 2014). Humic acid sodium salt (HA) and atrazine (ATR) were of technical/analytical grade (Sigma-Aldrich) and were used as received. Calcium sulphate, magnesium sulphate heptahydrate and sodium sulphate, all of analytical grade, were added to the feed solution to simulate the ionic strength and cation content $\left(\mathrm{Ca}^{2+} / \mathrm{Mg}^{2+} / \mathrm{Na}^{+}\right)$of typical surface waters (Karavoltsos et al., 2008). All solutions were prepared by deionized water buffered with $1 \mathrm{mM}$ sodium bicarbonate. Sulphuric acid was employed to adjust the feed solution $\mathrm{pH}$ close to 6.0-6.5, which was found to be near optimum for diclofenac degradation (Sarasidis et al., 2014). For such pH values, the $\mathrm{TiO}_{2}$ Aeroxide ${ }^{\oplus} \mathrm{P} 25$ surface remains positively charged $\left(\mathrm{pH}_{\mathrm{pzc}} \sim 6.7\right)$, thus, enhancing its affinity to the negatively charged ATR ( $\left.\mathrm{pKa} 1.7\right)$ due to electrostatic attractions; consequently, the attack of ATR by the reactive species formed on the photon-activated catalyst surface is facilitated. A HA stock solution was prepared and fed to the PMR after dilution with deionized water to a feed solution concentration of approx. 2, 5 and $8 \mathrm{mg} \mathrm{l}^{-1}$. Feed solutions were spiked with 50-100 $\mathrm{\mu g} \mathrm{I}^{-1}$ ATR concentrations which are an order of magnitude greater than those found in natural surface waters for accuracy of analysis. Total organic carbon (TOC) concentrations of samples collected from the feed and permeate stream were measured in a TOC analyzer (TOC-5000A, Shimadzu Co) without any pre-treatment as they did not contain any $\mathrm{TiO}_{2}$ particles. Off-line solid phase extraction (SPE) with gas chromatography, employing a micro-cell Electron Capture Detector ( $\mu$-ECD) was used to achieve the sensitivity required for the tested herbicide. An Agilent Technologies system was used comprising a 6890N GC fitted with an Agilent J\&W HP-5 $0.25 \mu \mathrm{m}, 30 \mathrm{~m}$ x $0.32 \mathrm{~mm}$ (i.d.) non-polar 
column and equipped with a $\mu$-ECD detector. Nitrogen was used as the carrier and make-up gas at a constant flow rate of $4.5 \mathrm{ml} \mathrm{min}^{-1}$ and $120 \mathrm{ml} \mathrm{min}^{-1}$, respectively. The temperature program was as follows: $160{ }^{\circ} \mathrm{C}$ for $1 \mathrm{~min}$, then from $160{ }^{\circ} \mathrm{C}$ to $250{ }^{\circ} \mathrm{C}$ at $15{ }^{\circ} \mathrm{C} \mathrm{min}-1$. The injector temperature was $250^{\circ} \mathrm{C}$. Injections $(1 \mu \mathrm{l})$ were made in a splitless injector mode. Simazine, a triazine compound similar to ATR, was used as internal standard in order to assess the recovery of ATR in the SPE-GC-ECD analyses. The SPE procedure followed is described in a previous paper (Plakas et al., 2006). The recoveries achieved with this procedure are in the range $73-108 \%$.

\subsection{Experimental procedure}

The experimental conditions employed are summarized in Table 1. Feed solutions of ATR with three different HA concentrations were photocatalytically treated in the absence or presence of background cations. The implemented automatic backwashing protocol (1/9) consisted of 1 min of backwashing after 9 min of filtration (suction). Furthermore, one experiment with no UV-A irradiation (Exp. No 1a) was performed in order to evaluate the possible adsorption of the relatively hydrophobic ATR in the experimental setup (i.e. adsorption on the $\mathrm{TiO}_{2}$ catalyst and the UF module), which would contribute to the apparent ATR concentration reduction during the photocatalysis tests. Moreover, the extent of UV-A photolysis on ATR degradation was assessed by applying UV-A for $8 \mathrm{~h}$ in the absence of $\mathrm{TiO}_{2}$ particles (Exp. No 2b). The PMR setup operated in continuous mode for all experiments lasting $28 \mathrm{~h}$.

Table 1. Summary of main experimental conditions and ATR removal results

\begin{tabular}{|c|c|c|c|c|c|c|c|}
\hline Exp. No. & $\begin{array}{l}\mathrm{TiO}_{2} \\
\left(\mathrm{~g} \mathrm{I}^{-1}\right)\end{array}$ & $\begin{array}{l}\mathrm{HA}_{\text {feed }} \\
\left(\mathrm{mg} \mathrm{I}^{-1}\right)\end{array}$ & $\begin{array}{c}\mathrm{Ca}^{2+} / \mathrm{Mg}^{2+} / \mathrm{Na}^{+} \text {feed } \\
\left(\mathrm{mg} \mathrm{I}^{-1}\right)\end{array}$ & $\begin{array}{l}\text { ATR }_{\text {feed }} \\
\left(\mu \mathrm{I}^{-1}\right)\end{array}$ & $\begin{array}{l}\text { UVA radiant } \\
\text { power per } \\
\text { unit volume } \\
\left(\mathrm{W} \mathrm{I}^{-1}\right)\end{array}$ & $\begin{array}{c}\text { ATR } \\
\text { removal } \\
(\%)\end{array}$ & $\begin{array}{c}\text { TOC removal } \\
(\%)\end{array}$ \\
\hline $1 a$ & \multirow{2}{*}{0.5} & \multirow{2}{*}{0} & \multirow{2}{*}{0} & 62.8 & 0 & $4.5 \pm 3.0$ & - \\
\hline $1 b$ & & & & 67.1 & 6.57 & $49.7 \pm 4.9$ & $23.0 \pm 1.7$ \\
\hline $2 a$ & \multirow{2}{*}{0} & \multirow{2}{*}{0} & \multirow{2}{*}{0} & 112.9 & 0 & 0 & - \\
\hline $2 b$ & & & & 121.5 & 6.57 & $11.2 \pm 2.4$ & - \\
\hline 3 & 0 & 5 & 0 & 94.7 & 0 & $16.9 \pm 0.5$ & - \\
\hline 4 & 0.5 & 5 & 0 & 102.4 & 6.57 & $98.4 \pm 1.6$ & $62.7 \pm 6.4$ \\
\hline 5 & 0.5 & 0 & $40 / 30 / 10$ & 61.8 & 6.57 & $87.8 \pm 3.3$ & $48.0 \pm 2.1$ \\
\hline 6 & 0.5 & 5 & $40 / 30 / 10$ & 99.4 & 6.57 & $93.1 \pm 1.9$ & $51.0 \pm 2.9$ \\
\hline 7 & 0.5 & 5 & $40 / 30 / 10^{a}$ & 96.7 & 6.57 & $88.4 \pm 2.0$ & $43.6 \pm 3.7$ \\
\hline $8 a$ & \multirow{2}{*}{0} & \multirow{2}{*}{0} & \multirow{2}{*}{$40 / 30 / 10$} & 127.8 & 0 & $38.7 \pm 6.8$ & - \\
\hline $8 b$ & & & & 105.8 & 6.57 & $37.2 \pm 4.5$ & - \\
\hline 9 & 0.5 & 2 & $40 / 30 / 10$ & 112.3 & 6.57 & $74.6 \pm 1.1$ & $37.8 \pm 2.4$ \\
\hline 10 & 0.5 & 8 & $40 / 30 / 10$ & 73.4 & 6.57 & $90.8 \pm 2.1$ & $51.4 \pm 4.8$ \\
\hline 11 & 0.5 & 5 & $80 / 60 / 20$ & 126.0 & 6.57 & $89.8 \pm 5.6$ & $55.8 \pm 9.8$ \\
\hline
\end{tabular}

${ }^{a}$ Addition of $\mathrm{CaCO}_{3}$ as calcium source (increased alkalinity)

\section{Results and discussion}

The experimental results concerning ATR removal during preliminary ultrafiltration runs (curried out only with UF membranes) are presented in Table 1 (Test No. 2a, 3, 8a). The results represent percentage removal at the end of the experiments during which steady state conditions have already been achieved; i.e. constant feed and time-averaged permeate flow rates with relatively constant ATR concentrations in the permeate solution. As expected, the negligible steric interactions between the membrane (mean pore size: $\sim 40 \mathrm{~nm})$ and ATR molecules $(\sim 0.788 \mathrm{~nm})$ resulted in negligible solute removal. However, the selected membrane exhibited the capability to reject ATR when HA or cations 
were present in the feed solution (16.9\% and 38.7\%, respectively). Relevant results from previous studies (Plakas and Karabelas, 2009; 2011) suggest that the retention of ATR tends to increase in the presence of HA due to the possible formation of HA-ATR pseudo-complexes which increase the steric exclusion of the complexes by the membrane. In the case of s-triazines, and especially ATR, this binding could be the result of ATR partitioning into the hydrophobic domains of HA molecules or the chemical binding to HA by ionic bond after the substitution of atrazine's chlorine atom (Piccolo et al., 1998). Surprisingly, the presence of cations, in concentrations that simulate typical surface waters (Karavoltsos et al., 2008) resulted in increased removal percentage compared to HA-ATR experiments. This trend may be attributed to the reduced diffusivity of ATR molecules through the membrane as a result of the competitive co-diffusion of free ATR molecules and of hydrated cations or cation-ATR complexes (Plakas and Karabelas, 2008). The latter can be formed due to electrostatic interactions between cations and the negatively charged ATR molecules ( $\mathrm{pH}>\mathrm{pKa})$.

The UV-Vis spectrum of ATR shows a maximum absorption at $221.5 \mathrm{~nm}$ with a negligible absorption at wavelengths greater than 290nm (UV spectrum data not shown here). This behaviour is in accord with the poorly photolytic degradation of ATR observed at the lamp emission band of the system (UV-A, $365 \mathrm{~nm}$ ), regardless of the presence of cations in the feed solution (Fig. 2). In turn, $\mathrm{TiO}_{2}$ photocatalysis was associated with an increased effectiveness. Specifically, under steady state conditions, the mean percentage ATR and TOC removal was $\sim 50 \%$ and $23 \%$, respectively, with no loss of $\mathrm{TiO}_{2}$ particles in the permeate stream. When cations were added in the feed solution the total degradation of ATR increased significantly ( $88 \%)$ in conjunction with a doubling of the mineralization $(48 \%)$. In accord with the preliminary ultrafiltration experiments, the positive effect of cations on overall ATR removal is probably linked to synergistic actions taking place within the PMR system, involving membrane diffusioncontrolled phenomena and photocatalytic degradation reactions of the free ATR molecules and/or the cation-ATR complexes formed under the specific conditions.

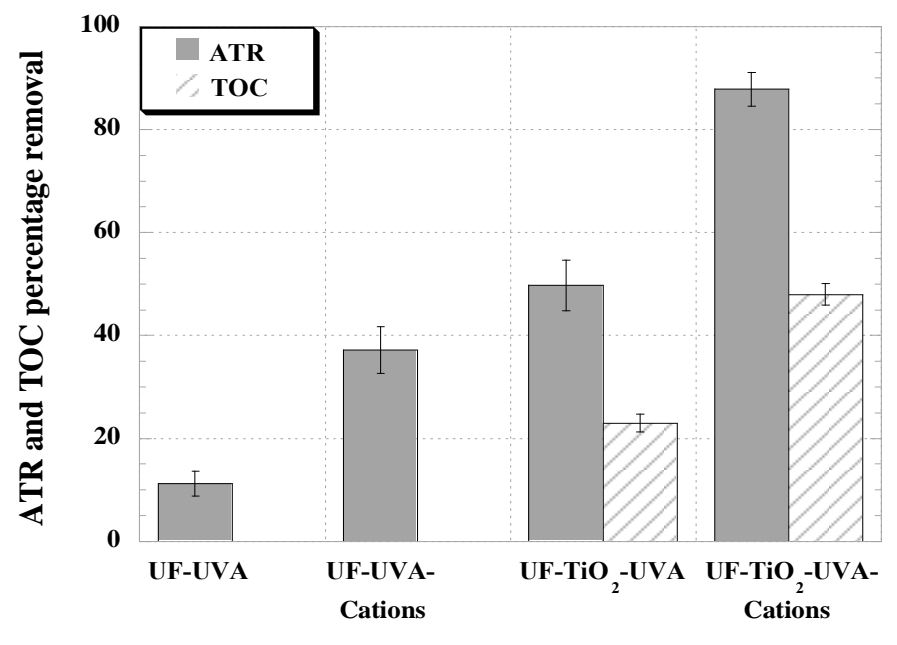

Figure 2. Effect of cations on ATR photolytic/photocatalytic removal/mineralization by the PMR system. Experimental conditions: $\left[\mathrm{TiO}_{2}\right]=0.5 \mathrm{gl}^{-1},[\mathrm{ATR}]_{\text {feed }}=\sim 100 \mu \mathrm{g} \mathrm{l}{ }^{-1},\left[\mathrm{Ca}^{2+}\right]=40 \mathrm{mg} \mathrm{l}^{-1}$, $\left[\mathrm{Mg}^{2+}\right]=30 \mathrm{mgl}^{-1},\left[\mathrm{Na}^{+}\right]=10 \mathrm{mg} \mathrm{l}^{-1}$

The influence of HA concentration on ATR removal and mineralization is depicted in Fig. 3. It is evident that, in the absence of cations, the treatment of synthetic water with both HA and ATR molecules result in almost complete removal of the latter. Specifically, after 28 hours of continuous operation, a 98\% ATR and $\sim 63 \%$ TOC removal were recorded. Taking into consideration the results of the preliminary ultrafiltration runs (Table 1), the increased removal rate of ATR is likely due to the enhanced $\mathrm{TiO}_{2}$ photocatalytic activity in the presence of HA in the feed solution. According to the literature, irradiated HA solutions can generate photochemical reactive intermediates (solvated electrons, hydroxyl radicals, singlet oxygen or substances in triplet states) which can also react with the target pollutants (Carlos et al., 2012). Moreover, the acceleration of ATR degradation may occur through a photosensitising 
process mediated by the dissolved HA (Konstantinou et al., 2001). These positive effects seem to overcome the increased UV-A absorption of the water samples due to the presence of the HA, resulting in an overall increase of the photocatalytic efficiency at higher HA concentrations in the range of 2 to 8 mg $I^{-1} H A$.

These results are also consistent with the low adsorption rates of the tested $\mathrm{HA}$ on the $\mathrm{TiO}_{2}$ surface at the experimental $\mathrm{pH}$ values (Patsios et al., 2013). Specifically, the neutral $\mathrm{pH}$ values are close to $\mathrm{TiO}_{2}$ $\mathrm{pH}_{\mathrm{pzc}}(6.7$ at $1 \mathrm{mM} \mathrm{NaCl}$ solution) (Sarasidis et al., 2014), leading to rather low electrostatic attraction with the negatively charged HA. Therefore, a rather small inhibition of ATR degradation is expected due to the competitive scavenging of $\mathrm{HO}^{\circ}$ by adsorbed $\mathrm{HA}$ molecules.

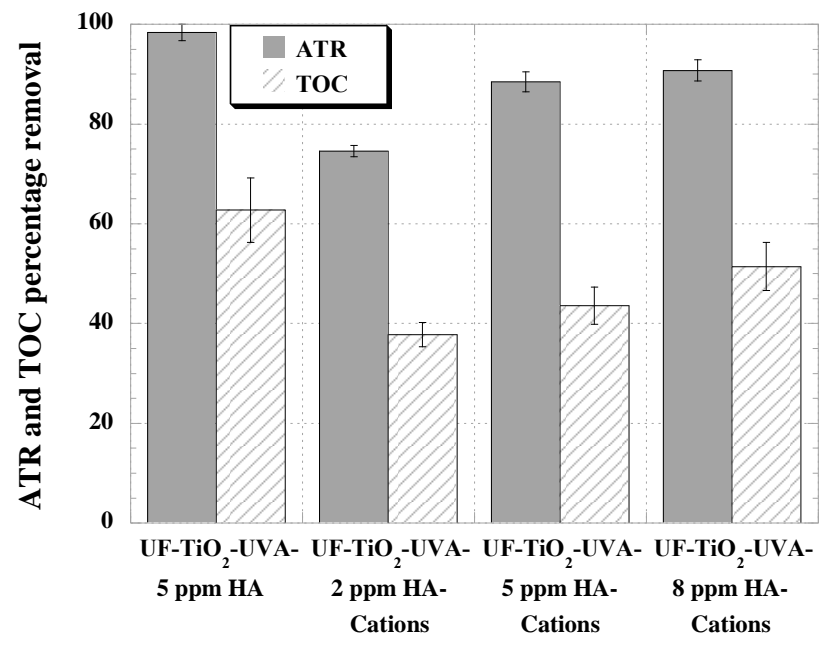

Figure 3. Effect of HA feed concentration on ATR and TOC percentage removal at steady state conditions $\left(\mathrm{t}=28 \mathrm{~h}\right.$ ). Experimental conditions: $\left[\mathrm{TiO}_{2}\right]=0.5 \mathrm{~g} \mathrm{l}^{-1},[\mathrm{ATR}]_{\mathrm{feed}}=\sim 100 \mu \mathrm{g} \mathrm{I}^{-1},\left[\mathrm{Ca}^{2+}\right]=40 \mathrm{mg} \mathrm{l}^{-1}$,

$$
\left[\mathrm{Mg}^{2+}\right]=30 \mathrm{mg} \mathrm{l}^{-1},\left[\mathrm{Na}^{+}\right]=10 \mathrm{mg} \mathrm{l}^{-1}
$$

According to Fig. 3, in contrast to results in the absence of HA (Fig. 2), cations may reduce the efficiency of the system, at a rate which slightly differs at various HA concentrations in the range tested. Specifically, ATR removal and TOC mineralization vary in the ranges from $~ 74$ to $91 \%$ and from $~ 38$ to $51 \%$, respectively, for HA concentrations of 2 to $8 \mathrm{mg} \mathrm{l}^{-1}$. According to Devitt et al. (1998), this reduction is probably due to the reduced association of ATR and HA, as a result of the occupation of interaction sites by the cations and/or the reduced access of ATR to HA sites due to changes in molecular conformation. This observation is also in agreement with the larger decline of ATR removal in the presence of double cation concentrations (Exp. No. 11). Increasing cation content results probably in charge shielding and neutralization of the HA's charged functional groups, thus shrinking the HA matrix. Previous experiments in this laboratory with different background NOM (water born humic and fulvic acids, NOM and tannic acids) showed a rather positive effect of cations (e.g. calcium) on ATR removal by NF and ULPRO membranes (Plakas and Karabelas, 2009). These seemingly contradictory results are attributed to the different types of membranes used as well as to the nature of the background NOM, since soil born HAs, like the Sigma-Aldrich reagent used in this study, may exhibit different acidity (carboxylic, phenolic) and elemental composition compared to the water-born natural organics used in previous works.

The increase of alkalinity in the feed solution $\left(40 \mathrm{mg} \mathrm{I}^{-1}\right.$ as $\left.\mathrm{CaCO}_{3}\right)$ resulted to a slight decrease of ATR removal (Exp. No 7) when treated together with HA. Specifically, ATR removal decreased from 93\% without bicarbonate ions to $\sim 88 \%$ in the presence of alkalinity. Autin et al. (2013) also observed the inhibition effect of alkalinity on the $\mathrm{UV} / \mathrm{TiO}_{2}$ photocatalysis of the pesticide metaldehyde, which was attributed to the formation of large $\mathrm{TiO}_{2}$ aggregates due to complexation reactions. Such reactions reduce the active surface of the catalyst and therefore, the production of oxidizing agents $\left(\mathrm{HO}^{\circ}\right)$ in the bulk. 

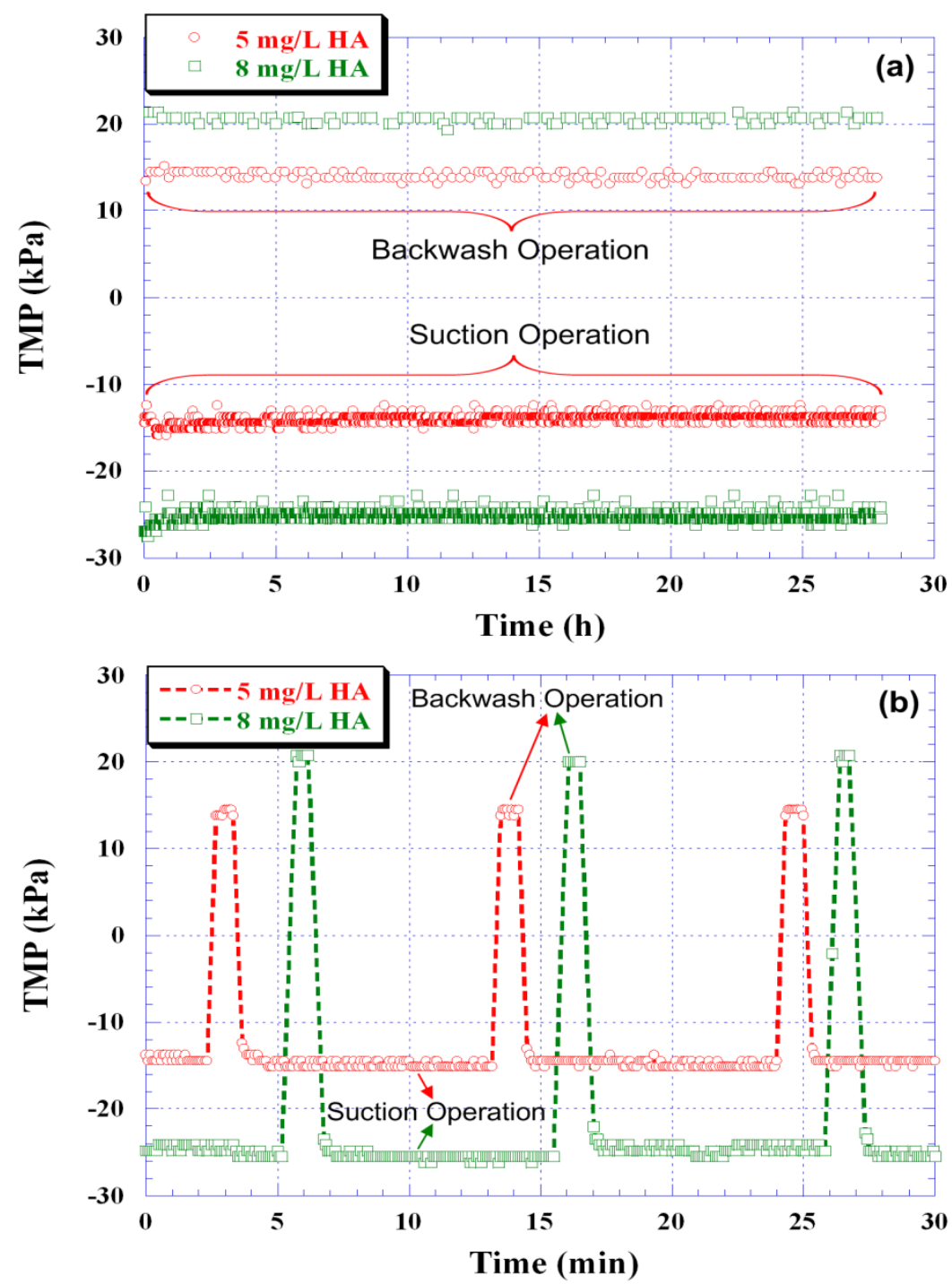

Figure 4. Temporal variation of trans-membrane pressure (TMP) during continuous operation of the PMR system for two different humic acid (HA) concentrations, a) recorded TMP values during the test, b) details of TMP profile for three subsequent filtration cycles

During the photocatalytic degradation of ATR in the presence of HA and cations at concentrations similar to those recorded in natural water sources, trans-membrane pressure (TMP) showed exactly the same behaviour in all experiments. In particular, TMP remained practically constant over a long time period, which is an indication of insignificant irreversible membrane fouling. Indeed, there was hardly any fouling layer formation, neither at the beginning nor at the end of the photocatalytic experiments. Typical TMP temporal profiles of two experiments, performed under otherwise identical conditions except HA concentration, are presented in Fig. 4, where negative values correspond to suction operation and positive values correspond to backwash operation. Obviously, TMP remains stable for the experimental period of $28 \mathrm{~h}$, at $13.8 \mathrm{kPa}$ and $25.5 \mathrm{kPa}$ when $5 \mathrm{mg} \mathrm{l}^{-1} \mathrm{HA}$ and $8 \mathrm{mg} \mathrm{l}^{-1} \mathrm{HA}$ are employed respectively, thereby allowing the successful continuous PMR operation under a moderate flux; i.e. $\left.15 \mathrm{I} \mathrm{m}^{-2} \mathrm{~h}^{-1}\right)$. Fig. 4 a also confirms that steady state conditions were attained within the first 5 hours of the PMR operation. Fig. 4b, includes TMP recorded values during 3 filtration cycles $(1 \mathrm{~min}$ backwashing after $9 \mathrm{~min}$ suction) over a period of $30 \mathrm{~min}$. This TMP stability essentially proves the effectiveness of the periodic backwashing operating mode of the specific system regarding the membrane filtration performance. Moreover, from these data it was concluded that experiments with higher HA concentrations result in higher values of TMP due to the higher fouling propensity. Similar results concerning TMP profiles were also obtained in the authors' previous studies (Patsios et al., 2013; 
Sarasidis et al., 2011) under different PMR system configuration, pollutant agent and backwashing conditions.

\section{Conclusions}

The present study focuses on the effects of background organic and inorganic species on ATR removal by a photocatalytic membrane reactor with suspended $\mathrm{TiO}_{2}$ nano-particles. It was demonstrated that in complex water matrices, various phenomena take place during photocatalytic generation of HO', ATR oxidation and separation by the membrane. These phenomena seem to enhance or reduce the overall efficiency of the process and the percentage removal of ATR, depending on conditions prevailing and species present in the feed-water. In general, a synergistic effect, giving rise to an improvement of the removal of ATR is observed in the presence of HA due to the possible formation of ATR-HA complexes, which in turn enhance the ATR removal by the membrane filter (from $49.7 \%$ without HA to $98.4 \%$ ). Experimental results with solutions of increased ionic strength, within the range likely encountered in drinking water sources (notably surface waters) reveal a positive effect of the dissolved cations ( $\mathrm{Ca}^{2+}$, $\mathrm{Mg}^{2+}, \mathrm{Na}^{+}$) on the overall removal of ATR by the PMR system (from $49.7 \%$ without cations to $87.8 \%$ with cations). The net outcome of the complicated interactions involved seems to favor the removal efficiency of ATR, and TOC in general. Specifically, in the presence of both HA and inorganic cations, in various concentrations, the overall ATR and TOC removal vary from 74 to $93 \%$ and from 38 to 51\%, respectively. Under all conditions the PMR system exhibited an efficient continuous operation confirming the negligible membrane fouling and the successful application of the automatic backwashing protocol (e.g. 1 min backwashing after 9 min filtration). In conclusion, the hybrid PMR system is capable of efficiently degrading ATR under conditions mimicking typical surface water, which holds promise for significant practical water treatment applications. A significant point that merits further examination is the significance of the background NOM character on the organic micropollutant removal by the PMR system. Research on this topic is in progress in this laboratory by monitoring the removal efficiency of different pesticide molecules (ATR and two of its derivatives among them) during the treatment of synthetic solutions of different NOM surrogates and/or during the treatment of natural water.

\section{References}

Ackerman F. (2007), The economics of atrazine, International Journal of Occupational and Environmental Health, 13, 437-445.

Ahmed S., Rasul M.G., Brown R. and Hashib M.A. (2011), Influence of parameters on the heterogeneous photocatalytic degradation of pesticides and phenolic contaminants in wastewater: A short review, Journal of Environmental Management, 92, 311-330.

Andreozzi R., Marotta R., Pinto G. and Pollio A. (2002), Carbamazepine in water: persistence in the environment, ozonation treatment and preliminary assessment on algal toxicity, Water Research, 36, 2869-2877.

Augugliaro V., Bellardita M., Loddo V., Palmisano G., Palmisano L. and Yurdakal S. (2012), Overview on oxidation mechanisms of organic compounds by $\mathrm{TiO}_{2}$ in heterogeneous photocatalysis, Journal of Photochemistry and Photobiology C: Photochemistry Reviews, 13, 224-245.

Australian Pesticides and Veterinary Medicines Authority (APVMA), Chemicals in the News: Atrazine, http://www.apvma.gov.au/news media/chemicals/atrazine.php (accessed April 1, 2014).

Autin O., Hart J., Jarvis P., MacAdam J., Parsons S.A. and Jefferson B. (2013), The impact of background organic matter and alkalinity on the degradation of the pesticide metaldehyde by two advanced oxidation processes: $\mathrm{UV} / \mathrm{H}_{2} \mathrm{O}_{2}$ and $\mathrm{UV} / \mathrm{TiO}_{2}$, Water Research, 47, 2041-2049.

Benotti M.J., Stanford B.D., Wert E.C. and Snyder S.A. (2009), Evaluation of a photocatalytic reactor membrane pilot system for the removal of pharmaceuticals and endocrine disrupting compounds from water, Water Research, 43, 1513-1522. 
Carlos L., Mártire D.O., Gonzalez M.C., Gomis J., Bernabeu A., Amat A.M. and Arques A. (2012), Photochemical fate of a mixture of emerging pollutants in the presence of humic substances, Water Research, 46, 4732-4740.

Devitt E.C., Ducellier F., Cöté P. and Wiesner M.R. (1998), Effects of natural organic matter and the raw water matrix on the rejection of atrazine by pressure-driven membranes, Water Research, 32, 2563-2568.

Doll T.E. and Frimmel F.H. (2005a), Photocatalytic degradation of carbamazepine, clofibric acid and iomeprol with P25 and Hombikat UV100 in the presence of natural organic matter (NOM) and other organic water constituents, Water Research, 39, 403-411.

Doll T.E. and Frimmel F.H. (2005b), Removal of selected persistent organic pollutants by heterogeneous photocatalysis in water, Catalysis Today, 101, 195-202.

Doll T.E. and Frimmel F.H. (2005c), Cross-flow microfiltration with periodical back-washing for photocatalytic degradation of pharmaceutical and diagnostic residues-evaluation of the long-term stability of the photocatalytic activity of $\mathrm{TiO}_{2}$, Water Research, 39, 847-854

Esplugas S., Bila D.M., Krause L.G.T. and Dezotti M. (2007), Ozonation and advanced oxidation technologies to remove endocrine disrupting chemicals (EDCs) and pharmaceuticals and personal care products (PPCPs) in water effluents, Journal of Hazardous Materials, 149, 631-642.

Haroune L., Salaun M., Ménard A., Legault C.Y. and Bellenger J.-P. (2014), Photocatalytic degradation of carbamazepine and three derivatives using $\mathrm{TiO}_{2}$ and $\mathrm{ZnO}$ : Effect of $\mathrm{pH}$, ionic strength, and natural organic matter, Science of the Total Environment, 475, 16-22.

Karabelas A.J., Sarasidis V.C. and Patsios S.I. (2013), The effect of UV radiant power on the rate of polysaccharide photocatalytic mineralization, Chemical Engineering Journal, 229, 484-491.

Karavoltsos S., Sakellari A., Mihopoulos N., Dassenakis M. and Scoullos M.J. (2008), Evaluation of the quality of drinking water in regions of Greece, Desalination, 224, 317-329.

Konstantinou I.K., Zarkadis A.K. and Albanis T.A. (2001), Photodegradation of selected herbicides in various natural waters and solis under environmental conditions, Journal of Environmental Quality, 30, 121-130.

Matilainen A. and Sillanpää M. (2010), Removal of natural organic matter from drinking water by advanced oxidation processes, Chemosphere, 80, 351-365.

Molinari R., Caruso A., Argurio P. and Poerio T. (2008), Degradation of the drugs Gemfibrozil and Tamoxifen in pressurized and de-pressurized membrane photoreactors using suspended polycrystalline $\mathrm{TiO}_{2}$ as catalyst, Journal of Membrane Science, 319, 54-63.

Mozia S. (2010), Photocatalytic membrane reactors (PMRs) in water and wastewater treatment. A review, Separation and Purification Technology, 73, 71-91.

Patsios S.I., Sarasidis V.C. and Karabelas A.J. (2013), A hybrid photocatalysis-membrane continuous process for degradation of refractory organic matter, Separation and Purification Technology, 104, 333-341.

Piccolo A., Conte P., Scheunert I. and Paci M. (1998) Atrazine interactions with soil humic substances of different molecular structure, Journal of Environmental Quality, 27, 1324-1333.

Plakas K.V. and Karabelas A.J. (2008), Membrane retention of herbicides from single and multi-solute media: The effect of ionic environment, Journal of Membrane Science, 320, 325-334

Plakas K.V. and Karabelas A.J. (2009), Triazine retention by nanofiltration in the presence of organic matter: The role of humic substance characteristics, Journal of Membrane Science, 336, 86-100.

Plakas K.V. and Karabelas A.J. (2011), A systematic study on triazine retention by fouled with humic substances NF/ULPRO membranes, Separation and Purification Technology, 80, 246-261.

Plakas K.V., Karabelas A.J., Wintgens T. and Melin T. (2006), A study of selected herbicides retention by nanofiltration membranes-The role of organic fouling, Journal of Membrane Science, 284, 291-300.

Sarasidis V.C., Patsios S.I. and Karabelas A.J. (2011), A hybrid photocatalysis-ultrafiltration continuous process: The case of polysaccharide degradation, Separation and Purification Technology, 80, 73-80.

Sarasidis V.C., Plakas K.V., Patsios S.I. and Karabelas A.J. (2014), Investigation of diclofenac degradation in a continuous photocatalytic membrane reactor. Influence of operating parameters, Chemical Engineering Journal, 239, 299-311.

United States Environmental Protection Agency (USEPA), Atrazine Background, http://www.epa.gov/pesticides/factsheets/atrazine background.htm (accessed April 1, 2014). 